\title{
GASTRIC SECRETION. III. THE ABSORPTION OF HEAVY WATER FROM POUCHES OF THE BODY AND ANTRUM OF THE STOMACH OF THE DOG
}

\author{
By OLIVER COPE, HESTER BLATT, AND MARGARET R. BALL \\ (From the Surgical Research Laboratories of the Harvard Medical School, \\ at the Massachusetts General Hospital, Boston)
}

(Received for publication August 7, 1942)

It is held as axiomatic that an understanding of the mechanism of the passage of substances from the blood stream to the gastric lumen must include a knowledge of the passage of these same substances in the reverse direction. In the previous paper (1), the absorption of radioactive sodium $\left(\mathrm{Na}^{24}\right)$ from the stomach was reported. Tangible amounts of $\mathrm{Na}^{24}$ placed in a stomach pouch were found after 15 minutes in the blood serum. From 1 to 7 per cent of the introduced base was absorbed from the acid bearing area during an hour, the amount depending upon whether the stomach was in a resting or secreting state; as much as $\mathbf{5 0}$ per cent was absorbed from the alkaline secreting antrum in the same period. The continuous passage of this basic ion into the body fluids altered significantly the concentrations of base in the gastric contents. Since it is probable that the sodium of neutral sodium chloride secreted into the pouch would be reabsorbed in a manner similar to the sodium introduced from the outside, it was concluded that the contents of an isolated pouch represents not true secretion but the resultant of secretion and absorption.

Water is an integral part of any secretion and the study of its exchange across the gastric membrane would seem essential for a comprehension of the control of electrolyte concentration in gastric juice. It has long been established $(2,3)$ that the contents of a gastric pouch is isotonic with the blood plasma, and it has been assumed, therefore, that the secretion itself is isotonic. It might be that the actual product secreted by a cell is not isotonic but that equilibrium with the internal fluids is rapidly reached by the exchange of water through a neighboring cell. Examples of the ability of the body to handle fluids other than isotonic are not wanting; the intestinal tract can absorb large quantities of water, and the kidney produces urine far to either side of isotonic.
The absorption of water from the whole stomach or one of its parts has not been demonstrated. Many years ago Pavlov showed that water was a mild stimulant of gastric secretion (4). Thus, if water is inserted into an isolated pouch of the stomach, with the passage of time there is a net gain in volume. It is possible, however, that as the solutions of electrolytes are flowing into the stomach and increasing the volume of the gastric pouch contents, there is a simultaneous absorption of a lesser volume of water.

It was decided to answer this question of the absorption of water from the stomach, using deuterium oxide or so called heavy water $\left(\mathrm{D}_{2} \mathrm{O}\right)$. This substance can be distinguished from ordinary water $\left(\mathrm{H}_{2} \mathrm{O}\right)$ by physical means, and by its greater density, and offers, therefore, the ideal for such an experiment.

Heavy water has been used in other parts of the animal body as a tracer substance to demonstrate the direction and rapidity of shift of water from one compartment to another. Recently Kinsey, Grant, and Cogan (5) have measured by means of $\mathrm{D}_{2} \mathrm{O}$ the flow of water into and out of the eye. The rapidity and volume of exchange found was surprising. In rabbits, one half of the water of the aqueous humor was replaced every 2.7 minutes. In the monkey, the exchange was slower, taking 7 minutes for one half to shift. The exchange of water out of the vitreous humor of the rabbit was somewhat slower than from the aqueous.

Animals have been observed to assimilate $\mathrm{D}_{2} \mathrm{O}$ much as they do $\mathrm{H}_{2} \mathrm{O}$. Only in high concentrations and over long periods have organisms shown intolerance to $\mathrm{D}_{2} \mathrm{O}$ (6). For experiments of short duration or when small quantities are used, $\mathrm{D}_{2} \mathrm{O}$ can be considered to be handled by the organism much as is $\mathrm{H}_{2} \mathrm{O}$.

\section{METHODS}

Two large male dogs were used, one with a pouch of the body, or acid bearing area of the stomach, and the 


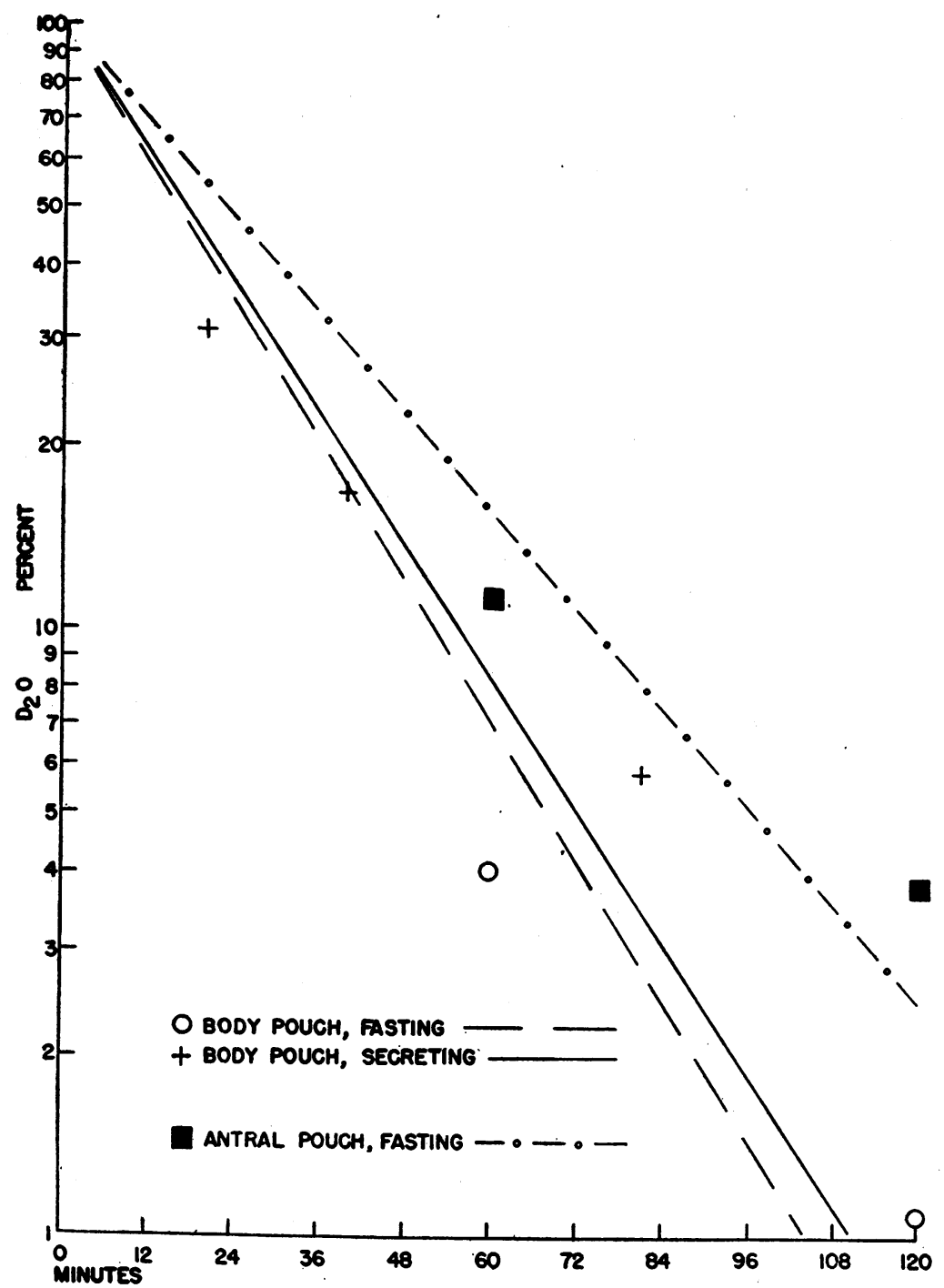

Fig. 1. Percentage of $\mathrm{D}_{2} \mathrm{O}$ Remaining in Body and Antral Pouches, Fasting and Secreting, at Intervals After Insertion

The percentage is plotted on a logarithmic scale. Fifty per cent of the $D_{2} \mathrm{O}$ had been absorbed from the pouch at approximately 20 minutes.

other with a pouch of the antrum. The preparation and care of such pouches has been described in previous papers $(7,1)$.

The exchange of water across the gastric membrane was measured by the rate of absorption of $\mathrm{D}_{2} \mathrm{O}$ from the pouch into the animal. A known volume of $\mathrm{D}_{2} \mathrm{O}$ was inserted into the pouch and its decreasing concentration measured at intervals. The $\mathrm{D}_{2} \mathrm{O}$ determinations were made for us by Dr. Kinsey and Dr. Grant, to whom we are greatly indebted. The details of the method are described in their paper (5). The $\mathrm{D}_{2} \mathrm{O}$ and $\mathrm{H}_{2} \mathrm{O}$ were distilled off from the gastric fluid under partial vacuum. The specific gravity of the distillate was determined by means of a Linderstr $\varnothing \mathrm{m}$-Lang constant density gradient tube.

In the calculation of the percentage of $\mathrm{D}_{2} \mathrm{O}$ which had disappeared from the pouch, that is, had been absorbed into the animal, due account was taken of the volume of the aliquots removed from the pouch for the determinations, as well as the amount of secretion which was flowing into the pouch as measured by the increase in volume of pouch contents.

The $\mathrm{D}_{2} \mathrm{O}$ was made up as 10 per cent of the water of an isotonic $\mathrm{NaCl}$ solution. An isotonic solution was used in order to avoid the secretion of gastric juice caused by water or a hypertonic solution (8). A known quantity 
of phenolsulphonephthalein (P.S.P.) was added to the $\mathrm{D}_{2} \mathrm{O}$ salt solution, and its recovery from the pouch at the end of the experiment served as a check on the absence of leakage from the pouch. It has been shown by Wilhelmj (9) that P.S.P. is not absorbed from the whole stomach pouch.

The chemical determinations made on blood and gastric juice were by standard laboratory procedures.

\section{EXPERIMENTS}

Two experiments were performed on the dog with the pouch of the body, or acid secreting area of the stomach. In the first, the dog was fasting; the dog had not been fed for 48 hours but had been allowed free access to water. The resting state of the stomach was proven by

TABLE I

\section{$\mathrm{D}_{2} \mathrm{O}$ : Percentage remaining in pouches at intervals} after insertion

The dog with the body pouch weighed $21.7 \mathrm{kgm}$.; the dog with the antral pouch weighed $17.3 \mathrm{kgm}$.

\begin{tabular}{c|c|c|c|c|c|c|c}
\hline \hline & \multicolumn{3}{|c|}{ Minutes } & \multicolumn{2}{|c|}{ Date } \\
\cline { 2 - 5 } & 20 & 40 & 60 & 80 & 120 & 180 & \\
\hline $\begin{array}{c}\text { Body pouch } \\
\text { Fasting } \\
\text { Secreting }\end{array}$ & 31 & 17 & 4 & 6 & 1 & 0 & $\begin{array}{l}\text { December 11, 1941 } \\
\text { December 22, 1941 }\end{array}$ \\
\hline $\begin{array}{c}\text { Antral pouch } \\
\text { Fasting }\end{array}$ & & & 11 & & 4 & 0 & December 11, 1941 \\
\hline
\end{tabular}

a period of control observation before introducing the $\mathrm{D}_{2} \mathrm{O}$ solution; during the 4 hours before the onset of the experiment, the dog secreted only $5 \mathrm{cc}$. of an alkaline juice. Thirty cc. of the $\mathrm{D}_{2} \mathrm{O}$ salt solution were inserted by catheter. At the end of one hour, the entire contents of the pouch, $36.5 \mathrm{cc}$., was removed, an aliquot of $1.9 \mathrm{cc}$. taken for analysis and the remainder returned. At 2 hours, the contents measured $45 \mathrm{cc}$., and a $2.1 \mathrm{cc}$. aliquot was taken. At 3 hours, the end of the experiment, the contents measured $5.2 \mathrm{cc}$. In this experiment, there was a 90 per cent recovery of the P.S.P. After the final emptying of the pouch, $35 \mathrm{cc}$. of blood were removed from the femoral artery.

The percentage remaining at the hourly intervals of the original amount of $\mathrm{D}_{2} \mathrm{O}$ placed in the pouch is given in Table $I$ and shown graphically (broken line) on a logarithmic scale in Figure 1. The absorption of $\mathrm{D}_{2} \mathrm{O}$ was more rapid than anticipated; indeed, none of the $\mathrm{D}_{2} \mathrm{O}$ was detectable in the pouch contents at 3 hours. From the figure, it is apparent that 50 per cent of the $D_{2} \mathrm{O}$ was absorbed at approximately 17 minutes.

In order to ascertain the condition of the animal, additional observations were made. The gastric secretion was analyzed for $\mathrm{pH}$ and chloride content. An acid-base partition including protein, as well as an NPN and hematocrit, was determined on the blood. The figures are given in Table II; all of the blood findings were within normal limits. The original gastric pouch sample showed a fasting secretion but the later samples were consistent with a small amount of acid secretion.

In the second experiment, the dog was actively secreting hydrochloric acid-pepsin juice. Fed by stomach tube in the morning, 2 hours before starting the experiment, the dog was observed to secrete $74 \mathrm{cc}$. of acid juice during the hour before the experiment. After emptying the pouch, $30 \mathrm{cc}$. of the $\mathrm{D}_{2} \mathrm{O}$ salt solution were inserted by catheter. At 20 minutes, $40 \mathrm{cc}$. of contents were removed and a 2 cc. aliquot taken. At 40 minutes, $77 \mathrm{cc}$. were found and $2 \mathrm{cc}$. taken. At 80 minutes, the end of the experiment, $134 \mathrm{cc}$. were recovered. Ninety-seven per cent of the P.S.P. inserted was retrieved at the end. Thirty-five cc. of arterial blood were taken after the final emptying.

TABLE II

Gastric secretion and arterial blood studies on dogs with body and antral pouches

Where two figures are given for gastric secretion, the top one represents the determination done on the sample removed immediately prior to insertion of the $\mathrm{D}_{2} \mathrm{O}$, the one in italics, the determination done on the sample removed at the end of the experiment.

\begin{tabular}{|c|c|c|c|c|c|c|c|c|c|c|c|c|c|}
\hline \multirow{2}{*}{ State of pouch } & \multicolumn{2}{|c|}{$\begin{array}{l}\text { Gastric } \\
\text { secretion }\end{array}$} & \multicolumn{11}{|c|}{ Arterial blood } \\
\hline & $\mathrm{pH}$ & $\mathrm{Cl}$ & $\underset{\text { crit }}{\text { Hemato- }}$ & NPN & $\begin{array}{l}\text { Serum } \\
\text { protein }\end{array}$ & $\mathrm{Cl}$ & $\mathrm{CO}_{2}$ & PO، & $\begin{array}{c}\text { Lactic } \\
\text { acid }\end{array}$ & $\begin{array}{l}\text { Pyruvic } \\
\text { acid }\end{array}$ & $\begin{array}{l}\text { Total } \\
\text { base }\end{array}$ & $\mathbf{N a}$ & $\mathrm{Ca}$ \\
\hline Body pouch & & per ${ }_{\text {per. }}$. & $\begin{array}{c}\text { per cent } \\
\text { cells }\end{array}$ & $m g m$. & grams & pereq. & per $\begin{array}{c}\text { meq. } \\
\text { per }\end{array}$ & $m g m$. & mgm. & mgm. & $\underset{\text { per }}{\text { meq. }}$. & pere. & $\underset{\text { per }}{\text { meq. }}$. \\
\hline Fasting & $\begin{array}{l}8.2 \\
3.2\end{array}$ & $\begin{array}{l}118 \\
158\end{array}$ & 50 & 25 & 5.9 & 111 & 33 & 3.0 & 30 & 2.4 & 155 & 143 & 5.0 \\
\hline Secreting & $\begin{array}{l}1.0 \\
1.0\end{array}$ & $\begin{array}{l}157 \\
161\end{array}$ & 53 & 46 & 7.3 & 58 & 33 & 5.3 & 22 & 4.5 & 154 & 145 & 4.9 \\
\hline $\begin{array}{c}\text { Antral pouch } \\
\text { Fasting }\end{array}$ & $\begin{array}{l}1.8 \\
2.0\end{array}$ & 151 & 55 & 34 & 6.8 & 114 & 27 & 3.1 & 28 & 1.6 & 153 & 143 & 4.9 \\
\hline
\end{tabular}


The percentage of the $\mathrm{D}_{2} \mathrm{O}$ remaining at each withdrawal is given in Table $I$ and in Figure 1 (unbroken line). The apparent rate of absorption of the $\mathrm{D}_{2} \mathrm{O}$ from the actively secreting pouch did not differ from that observed when the animal was fasting. Sixty-nine per cent of the $\mathrm{D}_{2} \mathrm{O}$ had disappeared in 20 minutes. The curve reconstructed from the three points observed indicates again that 50 per cent was absorbed in approximately 17 minutes.

The gastric juice and blood determinations, made to evaluate the state of the animal, are given in Table II. The gastric pouch juice showed an active state of secretion. The blood findings were within the normal range except for a slightly elevated hematocrit, a high $\mathrm{CO}_{2}$ content, and low chloride concentration, pointing to partial chloride depletion.

One experiment was run on the dog with the antral pouch. The animal had not been fed for 24 hours prior to the experiment. The juice washed out of the pouch, however, was acid, $\mathrm{pH} 1.8$, suggesting a continued active secretion. Seven cc. of the $D_{2} O$ solution were used. Volumes were measured and aliquots were removed at hourly intervals. The final corrected volume was $10 \mathrm{cc}$., and there was essentially a total recovery of P.S.P. Thirty-three cc. of arterial blood were taken.

The figures for the percentage of $\mathrm{D}_{2} \mathrm{O}$ remaining in the pouch are given in Table II and in Figure 1. At 3 hours, all of the measurable $\mathrm{D}_{2} \mathrm{O}$ had been absorbed from the pouch. The slope of the disappearance or absorption rate of the $\mathrm{D}_{2} \mathrm{O}$ was slightly more gradual than that of the body pouch. The difference is not considered significant, however, in view of the few observations. The reconstructed curve intimates that half of the $\mathrm{D}_{2} \mathrm{O}$ had been absorbed in 23 minutes.

The antral juice and blood findings are recorded in Table II. The juice showed a continued active secretion; all of the blood findings are those of a normal dog.

\section{COM MENT}

If it is assumed that $\mathrm{D}_{2} \mathrm{O}$ and $\mathrm{H}_{2} \mathrm{O}$ cross the gastric membrane with equal facility and rapidity, then under the conditions of these experiments, half of the water within the pouch crosses the membrane in approximately each 20 minutes. The data available regarding exchange of water elsewhere in the body of experimental animals make such a rapid exchange reasonable. The observation by Kinsey et al. (5) that there is a different rate of transfer in the eye of the rabbit compared with that of the monkey suggests that the anatomically comparable cell membranes of certain animals may be more slowly permeable to water than those of others. The slower rate observed for the dog's stomach, as compared with the rab- bit's or monkey's eye, may be due to the fact that we are dealing with a different membrane, secretory rather than serous, or that it is a different animal.

Although the rate of exchange of water observed crossing the membrane of a gastric pouch in the dog may not be directly applicable to the human or other animal stomach, the observations of this paper certainly point to a rapid physiologic exchange of water in the stomach. The ability of the stomach to reach isotonicity between its contents and the body fluids is explained, and it lends a broader interpretation to the observations that water (4) and hypertonic fluids (8) are stimulants of gastric secretion.

\section{SUMMARY AND CONCLUSIONS}

The exchange of water across the gastric membrane has been investigated in the dog by observing the absorption of heavy water, deuterium oxide $\left(\mathrm{D}_{2} \mathrm{O}\right)$, from stomach pouches. One animal had a pouch of the body, or acid secreting portion of the stomach, and another a pouch of the gastric antrum. Under the conditions of the experiments, half of the $\mathrm{D}_{2} \mathrm{O}$ was absorbed in approximately 20 minutes.

There was no significant difference in the rate of absorption between the body and antral pouches. Whether the body pouch was in a secreting or resting state also made no difference.

If it is assumed that the gastric membrane handles $\mathrm{D}_{2} \mathrm{O}$ as it does $\mathrm{H}_{2} \mathrm{O}$, it can be concluded that there is a rapid exchange of $\mathrm{H}_{2} \mathrm{O}$ between the gastric contents and body fluids; such an exchange would be a major reason for their isotonicity.

\section{BIBLIOGRAPHY}

1. Cope, O., Cohn, W. E., and Brenizer, A. G., Jr., Gastric secretion. II. Absorption of radioactive sodium from pouches of the body and antrum of the stomach of the dog. J. Clin. Invest., 1943, 22, 103.

2. Gamble, J. L., and McIver, M. A., The acid-base composition of gastric secretions. J. Exper. Med., 1928, 48, 837.

3. Gilman, A., and Cowgill, G. R.; Osmotic relations between blood and body fluids. II. The osmotic relation of blood and gastric juice. Am. J. Physiol., 1933, 103, 143. 
4. Pavlov, I. P., The Work of the Digestive Glands. Charles Griffin \& Company, Ltd., London, 1910.

5. Kinsey, V. E., Grant, M., and Cogan, D. G., Water movement and the eye. Arch. Ophth., 1942, 27, 242.

6. Krogh, A., The use of deuterium in biological work. Enzymologia, 1938, 5, 185.

7. Cope, O., MacMahon, C. E., Hagströmer, A., and Thompson, R. H., Gastric secretion. I. A new gastric pouch with a non-leaking stoma and an intact nerve supply; description of a two stage technic used on the dog. Arch. Surg., 1940, 40, 717.

8. Cope, O., and Brenizer, A. G., Jr., Gastric secretion. IV. The influence of osmotic pressure of gastric contents on the volume of gastric secretion. (To be published.)

9. Wilhelmj, C. M., O'Brien, F. T., and Hill, F. C., The inhibitory influence of the acidity of the gastric contents on the secretion of the acid by the stomach. Am. J. Physiol., 1936, 115, 429. 